\title{
SYMPOSIUM
}

\section{Role of core and bridging groups in the transmission dynamics of HIV and STIs in Cotonou, Benin, West Africa}

\author{
C M Lowndes, M Alary, H Meda, C A B Gnintoungbé, L Mukenge-Tshibaka, C Adjovi, \\ A Buvé, L Morison, M Laourou, L Kanhonou, S Anagonou
}

Sex Transm Infect 2002;78(Suppl I):i69-i77

The potential for exposure of low and high risk women to HIV and sexually transmitted infections (STI) through unprotected sex with male clients of female sex workers in Cotonou could account for most if not all of the estimated yearly numbers of HIV infections in Cotonou women ( 1000). As ongoing transmission of HIV, and also of the most predominant STls such as gonorrhoea and HSV-2, appears to be largely fuelled by transmission within core and bridging groups in Cotonou, interventions targeted at both female sex workers and their male clients remain of the utmost importance and could have a significant effect on the evolution of HIV/STI epidemics in Benin.

See end of article for authors' affiliations

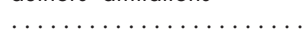

Correspondence to: Dr Catherine Lowndes, Department of Social Science and Medicine, Imperial College School of Medicine, Charing Cross Campus, Reynolds Building, St Dunstan's Road, London W6 8RP UK;

clowndes@gre.ulaval.ca

Accepted

30 November 2001
$M$ uch recent discussion on the dynamics of HIV epidemics has centred on the question of why the epidemic has progressed faster in some countries than others in subSaharan Africa. ${ }^{1}$ Various factors such as rates of male circumcision, timing of introduction of the epidemic and concomitant sexually transmitted diseases (STI), and rates of condom use may account for this. A better understanding of this question could contribute to our comprehension of the determinants of HIV epidemics and to how best to design effective preventive interventions. Furthermore, there is a need for a better understanding of the dynamics of HIV and STI epidemics at different stages of their evolution, and the significance of this for the design and implementation of preventive interventions. ${ }^{2}$

In this context, our objectives in this paper were to take the town of Cotonou, Benin, as a case study to examine some of these issues and their possible role in determining the course of the epidemic in Benin, which is characterised by a relatively low HIV prevalence in the general population and a high prevalence in female sex workers and their male clients. Cotonou is a suitable choice for such analyses as reliable data on sexual behaviour and STI/HIV rates are available for both low and high risk groups in the population.

The structure of the paper will be as follows: first, we will review currently available data from Cotonou on sexual behaviour and HIV/STI rates and trends in high and low risk groups of the population; second, using those data we will explore the transmission dynamics of HIV, focusing on the role of core groups in the epidemic in
Cotonou; third, we will discuss the implications of these analyses both for understanding the dynamics of the HIV epidemic in Cotonou and for the design of interventions for the prevention of sexually transmitted epidemics in general, taking into account STI-specific epidemic phases in Cotonou.

Another paper in this issue ${ }^{3}$ uses the data from Cotonou to model the possible effects of interventions currently being directed at high risk groups on the evolution of STI/HIV epidemics in high risk groups and in the general population in Cotonou.

\section{DATA SOURCES}

Several sources of data on STI/HIV rates and sexual behaviour in the general population and in groups at high risk are available for Cotonou. Data on the general population ${ }^{45}$ and some data on high risk groups ${ }^{6}$ are taken from a study of the heterogeneity of HIV in four African cities (Cotonou in Benin, Kisumu in Kenya, Ndola in Zambia, and Yaoundé in Cameroon), hereafter called the four cities study. In that study, a random sample of 1080 men and 1139 women aged 15 to 49 years from the general population in Cotonou was interviewed in a household based survey and gave blood and other samples for laboratory HIV and STI analyses. In addition, interviews were conducted with a sample of 433 sex workers. Data are also taken from the 1996 DHS survey. ${ }^{7}$ Other data sources used are sentinel HIV and syphilis serosurveillance data from National AIDS Control Programme (PNLS) yearly reports, reports from international and Beninese government agencies, as well as some additional research studies. In terms of groups at high risk, data are available from studies carried out by or in collaboration with the SIDAl/2 or West African AIDS project phases land 2, funded by the Canadian International Development Agency (CIDA). Data are available from clinic based studies carried out by the CIDA project in 1993, on men and women with STI symptoms ${ }^{8}$ and from pregnant women. ${ }^{9}$

A major focus of the SIDA2 project in Cotonou is on STI management and HIV prevention in female sex workers. SIDA2-supported free clinical STI management and active STI screening (using a clinical screening algorithm), ${ }^{10}$ as well as voluntary HIV counselling/testing and free condom provision, are available at a confidential clinic for female sex workers located within the largest public health centre (CSCU1) in Cotonou. Clinic 
outreach workers visit all known prostitution sites in Cotonou at regular intervals to carry out prevention activities and to encourage the sex workers to come to the STI clinic for regular medical check ups, whether or not they have obvious symptoms of STI. The number of visits by female sex workers to the clinic was 2468 in 1996, 2587 in 1997, and 3175 in 1998; between April 1996 and December 1999, 2957 episodes of STI were diagnosed and treated in 1152 sex workers at the clinic. ${ }^{11}$ In addition to routine data available from the STI clinic, three serial cross sectional surveys of HIV/STI prevalence and sexual behaviour in female sex workers attending the CIDA funded STI clinic in Cotonou were carried out in 1993, 1995-6, and 1998-9. ${ }^{10} 1213$

A study on clients and other sexual partners of female sex workers was carried out in Cotonou in 1998, in collaboration with the SIDA2 project. ${ }^{14}{ }^{15}$ Four hundred and four male clients of female sex workers were recruited on site at prostitution venues in Cotonou (13 different sites in seven areas of Cotonou; roughly half the sample was recruited in Jonquet and half in more peripheral areas), and provided a urine sample (for leucocyte esterase dipstick (LED), HIV, and STI testing) before having sex with a female sex worker. After having sex they underwent an interview and a physical examination for STI. The same study recruited 41 prostitution site personnel and 56 regular boyfriends of female sex workers in Cotonou.

\section{BENIN: COUNTRY PROFILE}

Benin is a small country of $112622 \mathrm{~km}^{2}$, bordered by Nigeria to the east, Togo to the west, Burkina-Faso and Niger to the north, and the Atlantic Ocean to the south. The estimated population of the country was 5970804 in 1998, of which $49 \%$ are aged under 15 years. ${ }^{16}$ Gross domestic product (GDP) per capita was US\$370 in 1995. Adult literacy rates for Benin are $48 \%$ for men and $23 \%$ for women (35\% overall). Discrimination against women is almost institutionalised, despite the adoption by the government of a convention against sex discrimination in 1992. Some ancestral customs are still very much enforced, particularly in rural areas, such as excision, forced marriage, confinement of young women before marriage, and leviratic inheritance of widows.

Cotonou is the main urban centre of the country and an important port, with a population of approximately 800000 . The proportion of single adult women in the population is higher in Cotonou than in Benin as a whole, at 39\% v 19\%, and the proportion of women in polygamous marriages is lower, although still considerable, at $31 \% v 50 \% .{ }^{17}$ School attendance rates among children aged $6-15$ years are $85 \%$ for boys and $53 \%$ for girls. ${ }^{17}$

\section{SEXUAL BEHAVIOUR AND STI/HIV RATES IN THE GENERAL POPULATION IN COTONOU \\ Demographics and sexual behaviour}

In the four cities study, nearly $100 \%$ of both men and women aged 20 or over in Cotonou reported that they were sexually active; this figure was $49 \%$ for men and $46 \%$ for women aged between 15 and 19 years in $1998 .{ }^{18}$ Median age at first sex was 18 for both men and women, and median age at first marriage 28 and 22 years, respectively. At time of interview, $43 \%$ of men and $64 \%$ of women were or had been married; $16 \%$ of married men reported polygamous marriages. The median age difference (as reported by men) between spouses was five years, and that between non-spousal partners was four years. $^{18}$

The median number of lifetime partners was four in men and two in women. Twelve per cent of married men reported more than one non-spousal sex partner in the last year; this figure was $20 \%$ in unmarried men (whether or not they had
Table 1 HIV prevalence in Benin and Cotonou, selected populations

\begin{tabular}{|c|c|c|}
\hline \multicolumn{2}{|l|}{ Study population } & $\begin{array}{l}\text { Prevalence } \\
\text { of HIV }\end{array}$ \\
\hline \multicolumn{3}{|l|}{ Benin: } \\
\hline \multirow{4}{*}{$\begin{array}{l}\text { PNLS sentinel surveillance data } \\
\text { Pregnant women urban areas: }\end{array}$} & & \\
\hline & 1990 & $0.5 \%$ \\
\hline & 1993 & $0.7 \%$ \\
\hline & 1997 & $1.9 \%$ \\
\hline \multirow[t]{3}{*}{ Pregnant women rural areas: } & 1990 & $0.2 \%$ \\
\hline & 1993 & $0.3 \%$ \\
\hline & 1997 & $5.6 \%$ \\
\hline \multicolumn{3}{|l|}{ Cotonou } \\
\hline \multicolumn{3}{|l|}{ PNLS sentinel surveillance data } \\
\hline \multirow[t]{4}{*}{ Pregnant women: } & 1990 & $0.4 \%$ \\
\hline & 1993 & $0.5 \%$ \\
\hline & 1996 & $1.5 \%$ \\
\hline & 1999 & $2.5 \%$ \\
\hline \multirow[t]{2}{*}{ STI clinic attenders: } & 1993 & $3.7 \%$ \\
\hline & 1998 & $2.8 \%$ \\
\hline \multicolumn{3}{|l|}{ Other data sources } \\
\hline \multicolumn{3}{|l|}{$\begin{array}{l}\text { General population, men 1997-8 } \\
\text { (four cities study, } n=928 \text { ) }\end{array}$} \\
\hline \multicolumn{2}{|l|}{$\begin{array}{l}\text { General population, women 1997-8 } \\
\text { (four cities study, } n=1015 \text { ) }\end{array}$} & $3.4 \%$ \\
\hline \multicolumn{2}{|l|}{ Pregnant women 1993 (SIDA2; $n=403$ ) } & $2.5 \%$ \\
\hline \multicolumn{2}{|l|}{ STI clinic men 1993 (SIDA2; $n=128$ ) } & $1.0 \%$ \\
\hline \multirow{2}{*}{\multicolumn{2}{|c|}{$\begin{array}{l}\text { STI clinic women } 1993 \text { (SIDA2; } n=211 \text { ) } \\
\text { FSW } 1993(\text { (SIDA2; } n=374 \text { ) }\end{array}$}} & $2.1 \%$ \\
\hline & & $53.3 \%$ \\
\hline \multicolumn{2}{|l|}{ FSW 1995-6 (SIDA2; n=350) } & $49.4 \%$ \\
\hline \multicolumn{2}{|l|}{ FSW 1998-9 (SIDA2; $n=590$ ) } & $40.7 \%$ \\
\hline \multirow{2}{*}{\multicolumn{2}{|c|}{$\begin{array}{l}\text { Clients of FSW, } 1998 \text { (SIDA2; } n=404 \text { ) } \\
\text { Boyfriends of FSW, } 1998 \text { (SIDA2;n=56) }\end{array}$}} & $8.4 \%$ \\
\hline & & $16.1 \%$ \\
\hline
\end{tabular}

FSW, female sex worker; STI sexually transmitted infection.

ever had sex). Corresponding figures for married and unmarried women were approximately $0.8 \%$ and $5 \%{ }^{18}$ Frequent condom use with all non-spousal partners of the past year was reported by $21 \%$ of men and $11 \%$ of women who had such partnerships. ${ }^{19}$ As a crude estimate of concurrency, $6.4 \%$ of all never-married men reported more than one ongoing partnership at the time of interview; and $6.5 \%$ of all men reported at least one partnership where money was exchanged for sex in the last year (Buvé A, personal communication).

Circumcision is nearly universal in men in Cotonou: $99.1 \%$ of men interviewed in the four cities study were circumcised, the vast majority before age at first $\operatorname{sex}^{20}$; in the study of clients and other sexual partners of female sex workers, all but one of the 501 men taking part in the study had been circumcised. ${ }^{14}$

\section{HIV/AIDS}

The first case of AIDS in Benin was detected in 1985, and since then there has been a gradual but steady progression of HIV/ AIDS throughout the country, with increases in yearly numbers of reported cases as well as in sentinel prevalence figures. Overall, a gradual but significant increase in HIV prevalence in pregnant women has occurred over time, with, in recent years, more rapid increases in HIV prevalence occurring in some rural areas than in urban areas (table 1). This is largely due to localised epidemics observed in Dogbo (department of Mono) and Savalou (department of Zou), the causes of which remain to be investigated. The cumulative number of AIDS cases reported to WHO/UNAIDS for Benin was 3536 by the end of 1998, while WHO estimates put the cumulative number of HIV infections at around 106000 to end 1997, and of AIDS cases at around $26500 .{ }^{16}$ HIV-1 infection predominates very largely in Benin, and the majority of HIV-2 infections are mixed infections. ${ }^{21}$

In Cotonou, sentinel HIV prevalence in pregnant women increased over sixfold from $0.4 \%$ in 1990 to $2.5 \%$ in 1999 (table 
Table 2 Sexually transmitted infection rates in Cotonou

\begin{tabular}{|c|c|c|c|c|c|c|c|}
\hline & GC* & $\mathrm{CT}^{*}$ & $\mathrm{TV} \dagger$ & Candida & HSV-2f & Syphilis§§ & $\begin{array}{l}\text { Genital } \\
\text { ulcerfl }\end{array}$ \\
\hline General population men $15-49$ years; $n=928$ & $1.1 \% * *$ & $2.3 \% * *$ & - & - & $11.9 \%$ & $1.8 \%$ & $6.4 \%$ \\
\hline General population women $15-49$ years; $97-98 ; n=1015$ & $0.9 \% * *$ & $1.3 \% * *$ & $3.2 \% \dagger \dagger$ & - & $29.5 \%$ & $1.2 \%$ & - \\
\hline Pregnant women 1993 (SIDA2; n=403) & $2.0 \% \dagger \dagger$ & $2.7 \% \ddagger \ddagger$ & $17.0 \%$ & $34.4 \%$ & - & $2.2 \%$ & $9.4 \%$ \\
\hline STI clinic men urethral discharge 1993 (SIDA2; $n=128)$ & $39.0 \%$ & $7.6 \%$ & - & - & - & $4.8 \%$ & $3.7 \%$ \\
\hline STI clinic women vaginal discharge $1993(\mathrm{SIDA} 2 ; n=211)$ & $5.7 \%$ & $2.1 \%$ & $11.5 \%$ & $32.3 \%$ & - & $2.1 \%$ & $9.9 \%$ \\
\hline FSW 1993 (SIDA2; $n=374)$ & $43 \%$ & $9 \%$ & $8.8 \%$ & $16.0 \%$ & - & $9.1 \%$ & $16.8 \%$ \\
\hline FSW 1995-6 (SIDA2; $n=350)$ & $31 \%$ & $7 \%$ & $12 \%$ & $23 \%$ & - & $7 \%$ & - \\
\hline FSW 1998-9 (SIDA2; $\mathrm{n}=590$ ) & $21 \%$ & $4 \%$ & $9 \%$ & $9 \%$ & - & $2 \%$ & - \\
\hline Clients of FSW 1998 (SIDA2; $n=404)$ & $5.4 \% \S \S$ & $2.7 \% \S \S$ & $2.7 \%$ ๆ & - & - & - & $2.0 \%$ \\
\hline Boyfriends of FSW (SIDA2; $n=56)$ & $5.4 \% \S \S$ & $1.8 \% \S \S$ & $5.4 \%$ ๆ & - & - & - & $1.8 \%$ \\
\hline
\end{tabular}

*NG/CT Amplicor PCR on urethral or cervical swabs unless otherwise specified; †direct microscopy unless otherwise specified; $\ddagger$ serum ELISA; $§ R P R+$

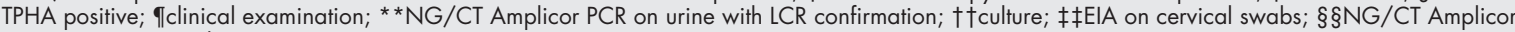
PCR on urine; II"in house" PCR.

CT, chlamydia trachomatis; FSW, female sex worker; GC, Neisseria gonorrhoea; PCR, polymerase chain reaction; STI, sexually transmitted infection; TV, Trichomonas vaginalis.

1). General population HIV prevalence ( 15 to 49 years) was $3.3 \%$ in men and $3.4 \%$ in women in 1997-8 (table 1), suggesting that equal proportions of men and women are currently infected with HIV in Cotonou. The highest HIV prevalence is seen in both men and women in the age group 25 to $29(6.7 \%$ in men and $4.8 \%$ in women $)^{4}$; however, as seen in the AIDS case data from Benin as a whole, women in Cotonou appear to become infected at younger ages than men (HIV prevalence in men and women aged 15 to $19: 0 \%$ and $2.4 \%$; aged 20 to 24 : $2.3 \%$ and $3.8 \%$, respectively). ${ }^{4}$

\section{Other STIs}

STI prevalence rates in Cotonou for selected populations are shown in table 2. STI rates appear to be somewhat higher in men than women in the general population, although HSV-2 seroprevalence rates are much higher in women than men. STI prevalences from the 1993 SIDA2 study of pregnant women are similar to rates seen in the general population of women in 1997-8, with the exception of $T$ vaginalis where the prevalence is much higher in pregnant women (table 2). Several sources of data indicate that syphilis prevalence/incidence is relatively low: prevalence of active syphilis was $1.8 \%$ in men and $1.2 \%$ in women in the general population in Cotonou in 1998 (table 2). Data on pregnant women in Cotonou indicate a prevalence of active syphilis of $2.2 \%$ in $1993^{\circ}$ and $0.57 \%$ in $1997 .{ }^{22}$

\section{STI clinic populations}

In the 1993 SIDAl/2 study on men and women consulting for STI symptoms, ${ }^{8} 68 \%$ of men with symptoms of urethritis reported more than one partner in the last year, compared with $11 \%$ of women with vaginal discharge. Over half the men $(56 \%)$ had had a new partner in the last three months, compared with only $7 \%$ of the women. It is very likely that a large proportion of the men's new partners were female sex workers. Indeed in a study on the aetiology of urethritis in West Africa, about half the men recruited in Cotonou reported that they had contracted their STI from a female sex worker. ${ }^{23}$ These figures contrast with pregnant women studied in the same year, ${ }^{9}$ where the data are much closer to the general population figures presented above: nearly all (98\%) had a regular partner, while only $1.5 \%$ reported more than one partner in the last year.

HIV prevalence was $1.0 \%$ in men with urethritis and $2.1 \%$ in women with vaginal discharge, in contrast to $2.5 \%$ in pregnant women (table 1). Sentinel HIV prevalence in STI patients was $0.5 \%$ in $1990,1 \%$ in $1992,3.7 \%$ in 1993 , and $2.8 \%$ in 1998 (table 1).

$N$ gonorrhoeae and C trachomatis rates in men with urethral discharge in Cotonou in 1993 were 39\% and 8\% (table 2). In women with vaginal discharge, $N$ gonorrhoeae and $C$ trachomatis prevalences were $5.7 \%$ and $2.1 \%$, respectively. This is in contrast to fairly equal (actually higher) rates of $C$ trachomatis in the general population than $N$ gonorrhoeae (table 2), and may reflect the asymptomatic nature of many chlamydial infections. Another possible explanation-at least for women-is the low sensitivity of polymerase chain reaction (PCR) for the detection of gonorrhoea in urine samples. ${ }^{24}$ In a recent study on men consulting for urethritis, ${ }^{23} \mathrm{~N}$ gonorrhoeae was detected in $65 \%$ of cases, $C$ trachomatis in $8 \%, T$ vaginalis in $8 \%$, and $M$ genitalium in $10 \%$ in Cotonou, showing (as in other countries in West Africa) the relatively much greater importance of $N$ gonorrhoeae than $C$ trachomatis in the aetiology of symptomatic urethritis. Syphilis rates in these populations are comparable to general population rates (table 2).

Recent unpublished analyses using PCR testing of samples from people consulting for genital ulcers in Cotonou identified chancroid (Haemophilus ducreyi) in $48 \%$ of cases and herpes (HSV-2) in $44 \%$, while $21 \%$ were of unknown aetiology, and syphilis was not identified in any samples (Pépin J, et al, unpublished results). Unfortunately, HIV testing was not performed in this study.

\section{SEXUAL BEHAVIOUR AND STI/HIV RATES IN CORE AND BRIDGING GROUPS IN COTONOU Female sex workers: demographics and sexual behaviour}

Prostitution in Benin-which is best described as a "semilegal" activity, as it is neither a criminal offence nor is it fully legalised-takes two major forms, overt and clandestine. Overt, "professional" prostitution is practised largely by foreign women in Cotonou, mainly from Ghana, Nigeria, and Togo (table 3), and tends to be the sole or major income source for these women, who operate mainly in brothels, bars, hotels, and nightclubs.

The highest concentration of visible prostitution in Cotonou is seen in Jonquet, the main downtown "nightspot" area. Female sex workers operate in the numerous hotels and bars there, many of which have rooms behind the barfront which are rented for sex work and often also for lodging. In this area, prostitution sites tend to have about 15 to 30 female sex workers per venue. Foreign (mainly Nigerian) as well as Beninese clients frequent this area (table 4 ), and the median price paid for a sex act in 1998 was $\$ 2$ (1000 FCFA).

In the more peripheral areas of Cotonou and in the central area of Placodji there are numerous more diffusely distributed maisons de passe, where female sex workers rent rooms solely for sex work; they sometimes also reside there. In these generally poorer prostitution sites, which tend to have between one and 10 female sex workers working per venue, the clients are largely Beninese, and prices paid per sex act are significantly lower than in Jonquet (table 4). 
Table 3 Demographic characteristics and sexual behaviour of female sex workers recruited at the SIDA2 STI clinic in Cotonou, 1993, 1995-6, and 1998-9

\begin{tabular}{|c|c|c|c|}
\hline & $1993 n=374$ & $1995-6 n=350$ & $1998-9 n=593$ \\
\hline Median age (interquartile range) & $30(26-35)$ & $28(25-34)$ & $27(23-33)$ \\
\hline \multicolumn{4}{|l|}{ Age group (years): } \\
\hline$<25$ & $17 \%$ & $22 \%$ & $34 \%$ \\
\hline $25-34$ & $56 \%$ & $54 \%$ & $45 \%$ \\
\hline$>34$ & $27 \%$ & $24 \%$ & $21 \%$ \\
\hline At least one steady partner & $58.6 \%$ & $71.0 \%$ & $73.5 \%$ \\
\hline Immigrants (born outside Benin) & $98 \%$ & $90 \%$ & $78 \%$ \\
\hline \multicolumn{4}{|l|}{ Nationality: } \\
\hline Ghanaian & $66 \%$ & $39 \%$ & $22 \%$ \\
\hline Nigerian & $11 \%$ & $37 \%$ & $38 \%$ \\
\hline Togolese & $20 \%$ & $12 \%$ & $15 \%$ \\
\hline Beninese & $2 \%$ & $10 \%$ & $22 \%$ \\
\hline Other & $1 \%$ & $2 \%$ & $3 \%$ \\
\hline Median years as FSW & - & 1.5 & 2 \\
\hline Reporting sex work as sole income & $65 \%$ & $60 \%$ & - \\
\hline Median (mean) No clients previous week & $17(19.4)$ & $25(25.6)$ & $7(12.9)$ \\
\hline Median (mean) No condoms with clients previous week & $10(12.5)$ & $12(14.9)$ & $5(9.9)$ \\
\hline Median (mean) No clients usually seen per week & $20(23.7)$ & $28(29.8)$ & $14(18.2)$ \\
\hline \multicolumn{4}{|l|}{ Median (mean) No clients seen last week by nationality of FSW } \\
\hline Nigeria & $22.5(25.7)$ & $22(23.1)$ & $10(14.4)$ \\
\hline Ghana & $16(18.7)$ & $28(28.4)$ & $16(18.3)$ \\
\hline Togo & $18(18.8)$ & $26(22.9)$ & $4(11.4)$ \\
\hline Benin & $10(16.9)$ & $25(26.7)$ & $4(8.1)$ \\
\hline \multicolumn{4}{|l|}{ Condom use with clients last week } \\
\hline Never & $12 \%$ & $6 \%$ & $12 \%$ \\
\hline Sometimes (1-49\%) & $19 \%$ & $31 \%$ & $20 \%$ \\
\hline Quite often (50-74\%) & $26 \%$ & $35 \%$ & $17 \%$ \\
\hline Very often $(75-99 \%)$ & $20 \%$ & $13 \%$ & $11 \%$ \\
\hline Always & $23 \%$ & $15 \%$ & $40 \%$ \\
\hline Median (mean) percentage condom use with clients last week & $66.7 \%(61.5 \%)$ & $58.3 \%(57.2 \%)$ & $75.0 \%(64.8 \%)$ \\
\hline
\end{tabular}

Clandestine prostitution, involving a wider definition of exchange of money, goods, services, or favours for sex, and where the women tend not to define themselves as prostitutes, is practised mainly by Beninese women, as well as by some foreigners, in Cotonou. These women are more difficult to identify and target for prevention activities, and less is known about them than about those who openly declare themselves as sex workers. ${ }^{25}$
There have been significant changes in the characteristics of the female sex worker population attending the SIDA2 STI clinic over time, with a decrease in the proportion of foreign sex workers who are Ghanaian and an increase in Nigerians (table 3). Also, the proportion of Beninese among female sex workers visiting the clinic has considerably increased. The median age of the female sex workers has decreased owing to the greater proportion of Nigerians and Beninese women in

Table 4 Clients of female sex workers recruited on-site at prostitution venues in Cotonou (1998): characteristics of whole sample and according to location of prostitution site in Cotonou

\begin{tabular}{|c|c|c|c|c|}
\hline & Whole sample $(n=404) \dagger$ & Jonquet $(n=232)$ & Outside Jonquet $(n=172)$ & $\mathrm{p}$ Value \\
\hline Median age (years) & 25.5 & 25 & 26 & $0.30 *$ \\
\hline Beninese nationality & $66.7 \%$ & $56.9 \%$ & $80.7 \%$ & $<0.001$ \\
\hline Lives in Cotonou & $84.0 \%$ & $77.8 \%$ & $93.3 \%$ & $<0.001$ \\
\hline Secondary level education & $52.1 \%$ & $58.5 \%$ & $43.0 \%$ & 0.006 \\
\hline Muslim religion & $25.8 \%$ & $35.4 \%$ & $11.9 \%$ & $<0.001$ \\
\hline Condom used with FSW just seen & $55.8 \%$ & $76.0 \%$ & $26.9 \%$ & $<0.001$ \\
\hline Median price paid to FSW just seen & \$US1 & \$US2 & \$USO.6 & $<0.001$ * \\
\hline Also visits FSW outside Cotonou & $19.2 \%$ & $24.4 \%$ & $11.8 \%$ & 0.006 \\
\hline \multicolumn{5}{|l|}{ Always uses condom with: } \\
\hline FSW & $39.0 \%$ & $53.2 \%$ & $18.8 \%$ & $<0.001$ \\
\hline Regular partner/wife & $13.1 \%$ & $16.8 \%$ & $7.8 \%$ & 0.037 \\
\hline Other non-FSW partners & $28.6 \%$ & $40.6 \%$ & $9.8 \%$ & $<0.001$ \\
\hline HIV prevalence & $8.4 \%$ & $6.0 \%$ & $11.6 \%$ & 0.049 \\
\hline N.gonorrhoeae (NG) prevalence & $5.4 \%$ & $2.6 \%$ & $9.3 \%$ & 0.004 \\
\hline C.trachomatis (CT) prevalence & $2.7 \%$ & $1.3 \%$ & $4.7 \%$ & 0.06 \\
\hline T.vaginalis (TV) prevalence & $2.7 \%$ & $2.6 \%$ & $2.9 \%$ & 1.00 \\
\hline NG/CT prevalence & $7.7 \%$ & $3.4 \%$ & $13.4 \%$ & $<0.001$ \\
\hline NG/CT/TV prevalence & $10.1 \%$ & $6.0 \%$ & $15.7 \%$ & 0.001 \\
\hline Current urethritis symptoms & $6.1 \%$ & $4.1 \%$ & $9.0 \%$ & 0.071 \\
\hline Genital ulcer on physical exam. & $2.0 \%$ & $1.1 \%$ & $3.2 \%$ & 0.238 \\
\hline Positive LED test & $8.4 \%$ & $6.0 \%$ & $11.6 \%$ & 0.045 \\
\hline Lifetime history of STI & $49.2 \%$ & $44.8 \%$ & $55.6 \%$ & 0.055 \\
\hline
\end{tabular}


Table 5 Clients of female sex workers (1998): data on sexual partners and STI/HIV rates

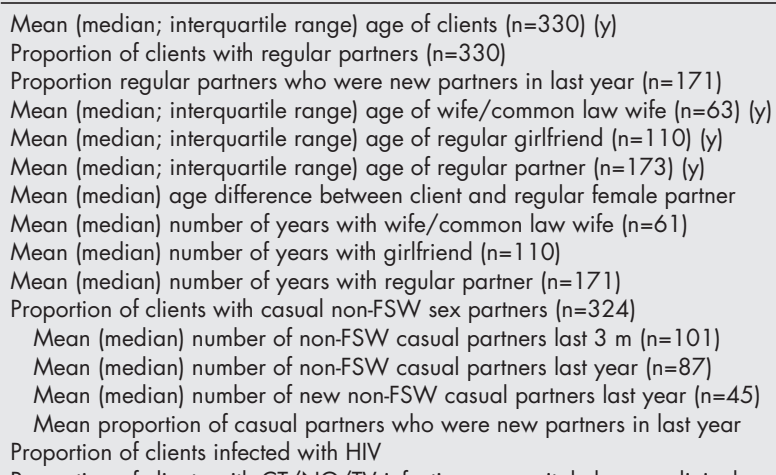

the sample, who tend to be younger than Ghanaian and Togolese sex workers (median age by nationality in 1998-9 was 24, 27,32 , and 32 years, respectively).

A decrease in median numbers of clients per week is seen over time (table 3), and in 1998-9, Ghanaian and Nigerian female sex workers reported higher numbers of clients per week than the Togolese and Beninese sex workers. In 1998-9, $51 \%$ of female sex workers reported having used a condom with at least $75 \%$ of clients in the previous week (table 3 ). Consistent condom use rates by female sex workers are much lower (14\%) with regular partners than with clients.

\section{Rates of HIV and other STIs and their evolution over time in female sex workers in Cotonou}

A rapid and very dramatic increase in HIV prevalence occurred in female sex workers in Cotonou in the early years of the epidemic. HIV prevalence increased from $3.3 \%$ in $1986^{26}$ to $8.0 \%$ in 1988 (PNLS, unpublished data) to $31 \%$ in $1990,{ }^{27}$ and it peaked at $53.0 \%$ in $1993^{28}$ (table 1 ). HIV rates were over 10 -fold higher in female sex workers than in women in the general population in Cotonou in 1998-9, at 40.7\% (table 1). Similarly, $\mathrm{Ngonorrhoeae}$ rates in female sex workers in Cotonou are extremely high, and over 20-fold higher than in women in the general population, while $C$ trachomatis rates are only three times as high (table 2). The four cities study reported a HSV-2 seroprevalence of $91 \%$ in female sex workers in 1997-8. ${ }^{6}$ Genital ulcer (clinical examination) rates were also high in female sex workers in Cotonou in 1993 (table 2).

As would be expected for an incurable disease, HIV prevalence in female sex workers increases with increasing age, and in those aged 35 years and older it is double that in those aged less than 25 years (60\% v 29\%). HIV prevalence is relatively low in Beninese sex workers (19\%) and very much higher in Ghanaian, Nigerian, and Togolese sex workers $(57 \%$, $36 \%$, and $55 \%$, respectively). Differences in gonorrhoea rates by nationality parallel those for HIV: gonorrhoea prevalence is lowest in Beninese female sex workers (7\%) and highest in Ghanaians (30\%). ${ }^{13}$

Since 1993 (the year the SIDAl/2 intervention was introduced), HIV rates have decreased in female sex workers in Cotonou. However, in a multivariate analysis controlling for changing demographic characteristics over time, HIV prevalence was stable, whereas there was a marked decrease in the prevalence of gonorrhoea and syphilis. This is in contrast to other provinces in Benin which have seen dramatic increases in HIV prevalence in female sex workers, from 36\% in 1993 to $52 \%$ in $1995-6,{ }^{12}$ and suggests that the SIDA2 intervention may have contributed to controlling the HIV, gonorrhoea, and syphilis epidemics among female sex workers in Cotonou. ${ }^{13}$
Similar conclusions are drawn from mathematical modelling of the intervention, as presented by Boily et al in this issue. ${ }^{3}$

\section{Clients and regular partners of female sex workers in Cotonou: demographics, sexual behaviour, and STI/HIV rates}

Table 4 shows data from the 1998 study of clients and non-paying sexual partners of female sex workers. Most clients lived in Cotonou and had received secondary level education. The most common religion stated by the clients was Christian (68\%), followed by Muslim (26\%) (table 4).

Twenty seven per cent of the clients were married (of these, $11 \%$ were polygamous marriages), and a further $52 \%$ had a regular girlfriend. ${ }^{15}$ Clients had been married for an average of 5.8 years, and had been with their girlfriends for 2.2 years; however, $30 \%$ of clients' regular partners were new partners in the last year (table 5). The mean age difference between clients and their regular partner was 4.7 years. One third of the clients interviewed had other casual sex partners who were not female sex workers; this proportion was not significantly different for men with or without regular partners. ${ }^{15}$ Among men with casual partners who were not female sex workers, the mean number of such partners in the last year was 4.4, and on average 3.1 of these were new partners (table 5 ).

The median price paid to the female sex worker with whom the client had just had sex was \$USI (range \$0.6-\$6); 56\% of clients had just used a condom (table 4) and 54\% reported always or often using condoms with female sex workers in general. These figures agree well with those reported by the sex workers themselves (the mean condom use rate by female sex workers with clients in the previous week was $67 \%$, table $3)$. Condom use rates by clients with non-sex-worker partners are predictably lower (table 4 ). Only $10 \%$ of clients always use condoms with both female sex workers and their regular partners, while $22 \%$ never use them with either type of partner. ${ }^{15}$

In terms of regular partners of female sex workers, the majority of the 56 men who took part in the study were Beninese, in contrast to their female sex worker girlfriends. ${ }^{15}$ Nearly half $(45 \%)$ were involved in their girlfriend's work, most often finding clients and providing security. Two thirds (66\%) had another regular sex partner besides their sex worker girlfriend (11\% of these "other" regular partners were also female sex workers). Half of the boyfriends had other casual female sex worker partners, and $46 \%$ other casual partners who were not sex workers. ${ }^{15}$ Consistent condom use rates reported by regular partners with their female sex worker girlfriends (16\%) agree closely with those reported by the sex workers themselves (14\%). Such agreement, as for the clients, 
argues in support of the accuracy of the data collected from these populations.

HIV prevalence in male clients of female sex workers in Cotonou is several-fold higher than that in the general population, at $8.4 \%$ compared with $3.2 \%$ (table 1 ). The same is true for gonorrhoea prevalence (table 2); C trachomatis prevalence is, however, similar. Overall, $10.1 \%$ of clients had either a $C$ trachomatis, $N$ gonorrhoeae, or $T$ vaginalis infection (table 4 ). HIV prevalence in regular partners of female sex workers was twice that in clients (table 1), which is consistent with the very low rates of condom use with female sex workers in this population.

In the 1998 study, $49 \%$ of clients and $73 \%$ of regular partners of female sex workers had had at least one lifetime episode of STI, with around $90 \%$ reporting symptoms of urethritis and $10 \%$ reporting genital ulcers for the last episode. $^{14}$

\section{ANALYSIS OF THE TRANSMISSION DYNAMICS OF HIV AND STIS IN COTONOU}

Data presented in the preceding sections indicate that HIV and at least some STI prevalence rates are very much higher in female sex workers than in the general population, and are intermediate in clients and regular partners of sex workers. Condom use rates by clients with female sex workers are nonnegligible but suboptimal, and condom use rates with casual and regular non-sex-worker partners are considerably lower; furthermore, the clients have significant rates of concurrency and partner change. Taken together, these data suggest that female sex workers and their male clients, acting as core and bridging groups, have an important role in HIV/STI transmission in Cotonou. In order to investigate this further and attempt to quantify the role of commercial sex in propagation of HIV and STIs in Cotonou, we carried out analyses of sexual behaviour and networking using data from the 1998 study on clients of female sex workers in Cotonou.

\section{Size of core and bridging groups in Cotonou}

In order to quantify the role of commercial sex in the dynamics of the HIV epidemic in Cotonou, estimates of the size of both core and bridging groups are necessary, as well as data on sexual behaviour and STI/HIV rates in these groups.

In terms of the female sex workers themselves, a census carried out in 1997-in collaboration between the SIDA2 project and the four cities study-identified 1915 visible female sex workers in Cotonou. Male clients visit female sex workers an average of 32 times a year, and the median time since starting to visit sex workers is two years. ${ }^{15}$ Clients tend not to visit the same sex workers, and the average number of different sex workers seen per client in Cotonou during the three months before the interview was 2.4. ${ }^{15}$ Combining data from female sex workers in the four cities study ${ }^{6}$ with those from the 1998 clients' study, we estimate that at least 19970 men visit female sex workers a year in Cotonou: this is equivalent to around $13 \%$ of the male population aged 15 to 49 years (details of these calculations are available on request).

We thus work with estimates of at least 1900 female sex workers in Cotonou, and of 19970 different men who visit them in Cotonou each year.

\section{Exposure of female sex workers and non-sex worker women to HIV and STIs through contact with male clients of female sex workers}

Using data on the proportion of HIV positive clients (positive or indeterminate result; $9.2 \%$ ); and the proportion with STI pathogens as detected by PCR (C trachomatis, $N$ gonorrhoeae, $T$ vaginalis), genital ulcers on clinical examination, or a history of ulcer or urethral discharge during the three months before interview (19\%) (table 5)-in combination with sexual behaviour and condom use rates with female sex workers and non-sex-worker partners-we calculated the number of nonsex-worker female partners in Cotonou exposed to HIV infection or STIs or both through unprotected sex with clients of female sex workers. On average, eight low risk (non-sexworker) female partners per 100 clients would have been directly exposed to HIV infection through unprotected sex with clients of female sex workers in the last year; 65/100 would have been exposed to STI infection, and 2.3/100 simultaneously exposed to STI and HIV. If, then, 19970 men had contact with a female sex worker during the last year, 1598 non-sex-worker women in Cotonou would have been directly exposed to HIV infection through unprotected sex with clients in the last year, 13060 to STI infection, and 459 simultaneously exposed to STI and HIV. Assuming a population size of 160000 adult women in Cotonou, $1.0 \%$ of them would have been exposed to HIV, $8.2 \%$ to STI, and $0.29 \%$ simultaneously to STI and HIV in the last year, through unprotected sex with clients of female sex workers.

We also looked at the situation from the point of view of the female sex workers themselves and their exposure to HIV/STI from the male clients. The mean number of different female sex workers seen per client over the last three months was 2.4, and, using data on the frequency of visits to female sex workers by clients, we estimate that the mean number of female sex worker-client contacts per client in the last three months was 6.9. Using these data in conjunction with STI/HIV and condom use rates with female sex workers in the clients, the probability of a female sex worker seen by one of the clients participating in the study having at least one unprotected contact with an HIV positive participating client in the last three months is $22 \%$, with a STI positive participating client $43 \%$, and with an HIV+/STI+ participating client, $8 \%$. These calculations do not take into account the additional exposure of female sex workers to HIV/STI through unprotected sex either with clients not recruited into the study or with regular partners. Given that condom use rates are much lower with regular partners than with clients, that boyfriends of female sex workers often have concurrent relationships with several female sex workers, ${ }^{14}$ and that HIV prevalence rates are twice as high in regular partners of female sex workers as in clients (table 1), the likelihood is high of significant further exposure to STI/HIV, and indeed of transmission of STI/HIV within the female sex worker population through concurrency. Actual HIV incidence in female sex workers attending the SIDA2 clinic in Cotonou was 17.9 per 100 person-years in 1995-6, and 10.5 per 100 person-years in 1997-2000.

The above calculations (of which details are available on request) make several assumptions about sizes of core groups, and may represent overestimations owing to assumptions concerning incubation periods of STIs and so on. On the other hand, as available estimates of the size of the female sex worker population-and thus of the size of the client population -in Cotonou are clearly underestimates, all calculations carried out here are also underestimates. Thus, while the actual figures themselves may not be $100 \%$ accurate, they serve their purpose in presenting a picture of the extent to which known STI/HIV rates in female sex workers and their clients-in combination with known sexual behaviour patterns of clients with female sex workers and non-sex-worker partners-could account for STI and HIV propagation within the general population in Cotonou. Indeed, given that a reasonable estimate of the number of new HIV infections per year in women in Cotonou is around 1000 (there are an estimated 15000 new HIV infections in Benin a year, ${ }^{16}$ and Cotonou represents $13 \%$ of the population of Benin, which gives $\sim 2000$ cases in both men and women, and half that in women), our calculations suggest that HIV transmission from female sex workers through male clients to their non-sexworker female partners could account for most of these new infections. 


\section{DISCUSSION \\ Characteristics, nature and stage of HIV and STI epidemics in Benin/Cotonou \\ HIV}

In Benin, a gradual and sustained expansion of the HIV epidemic has taken place over the last 15 years. HIV prevalence is equal in men and women in Cotonou, in contrast to some other countries in sub-Saharan Africa, such as Kenya, Zambia, and Cameroon, where HIV prevalence rates are significantly higher in women. ${ }^{4}$ HIV prevalence in female sex workers in Cotonou is over 10-fold higher, and is also several-fold higher in male clients and regular partners of female sex workers, than in the general population.

While the HIV epidemic is clearly expanding in Cotonou and elsewhere in Benin, with the exception of a few areas with high HIV prevalence, an explosive increase in general population prevalence and numbers of AIDS cases/deaths has not yet occurred, as it has or is currently doing in some other countries in sub-Saharan Africa such as Zimbabwe, Malawi, Botswana, and South Africa, with HIV prevalences in the general population reaching more than $20 \% .{ }^{29}$

This may be due, in part, to a combination of sexual behaviour (relatively high age at first sex and small number of sexual partners among women from the general population) and male circumcision rates. In Cotonou, the HIV epidemic is characterised by a high initial concentration of HIV infections in female sex workers, and a slow outwards diffusion to their circumcised male clients, with cases of HIV transmission probably being highly linked to concurrent STI infections. After sufficient numbers of men are infected, outwards transmission of HIV to women in the general population starts to occur, but the latter hardly transmit the infection to other men in the general population, partly because they generally have low risk behaviour. In addition, taking into account that nearly all men are also circumcised before age at first sex in Cotonou, ${ }^{20}$ and given recent findings strongly supporting a protective effect of male circumcision for HIV infection, ${ }^{30}{ }^{31}$ it is very likely that-as seen in many other situations-non-sexworker women in the general population are at considerably greater risk of being infected by HIV through exposure to infected male partners than men in the general population are of being infected through sexual contact with non-sex-worker women. We can perhaps look at non-sex-worker HIV positive women in this situation as an epidemiological dead end, from whom ongoing transmission is unlikely to occur (apart of course from vertical transmission).

In this scenario, an HIV epidemic will occur which progresses moderately fast and peaks at very much lower levels than in countries with lower levels of male circumcision and higher levels of risky sexual behaviour in women in the general population. STIs in men may be a very important factor determining transmission rates in this context of high circumcision rates, and our transmission dynamics analyses suggest that, given STI/HIV and condom use rates by clients with non-sex-worker female partners, relatively large numbers of women in the general population would be simultaneously exposed to HIV and STI through unprotected sex with male clients.

\section{Other STls}

Gonorrhoea is currently the predominant bacterial STI in Cotonou, and $N$ gonorrhoeae is also the predominant aetiological agent of urethritis in men. As such, it could be responsible for a considerable proportion of the approximately 13000 exposures a year to STI of low risk women exposed to STIs through unprotected sex with male clients of female sex workers in Cotonou. As for HIV, gonorrhoea is substantially more prevalent in high risk than in low risk groups in the population, its transmission may currently be largely fuelled through core and bridging groups (followed by transmission to the general population of women), and it may still be in a concentrated epidemic phase. A significant decrease in $\mathrm{Ngon-}$ orrhoeae prevalence in female sex workers has occurred since 1993, which may in part be the result of the concomitant SIDA2 intervention ${ }^{13}$; such decreases should be reflected in corresponding decreases in prevalence in the general population, although time series data of gonorrhoea rates in the general population are not currently available to allow further analysis of this question.

Syphilis prevalence has decreased significantly in female sex workers since 1993 (concomitantly with the SIDA2 intervention), and is now relatively low in Cotonou, with similar prevalences in both core groups and the general population in 1998. Furthermore, unpublished data (mainly from female sex workers) suggest that syphilis is basically absent from genital ulcers in Cotonou and that the main causative agents are herpes simplex (HSV-2) and $H$ ducreyi (Pépin J, et al, unpublished data). Thus syphilis may be in a low endemic phase in Cotonou, with continuing transmission fuelled largely through core/bridge groups. Decreases in prevalence in the general population may thus be expected to occur, with some delay, as a result of decreased numbers of infections occurring in the core group, and there is some evidence for this in pregnant women, where prevalence was $2.2 \%$ in 1993 and $0.57 \%$ in 1997.

In contrast to gonorrhoea, the prevalence of chlamydial infection in 1998 was similar in female sex workers, their clients, and the general population, and chlamydia may also be in a low endemic phase in Cotonou. Furthermore, the small observed decrease over time in prevalence in female sex workers attending the SIDA2 clinic is not statistically significant after controlling for age and nationality in a multivariate analysis. ${ }^{13}$ Lower differentials in chlamydial than gonococcal prevalences between core groups and the general population may reflect the fact that female sex workers are relatively old (median age 27 years), and be linked to the possible development of immunity in highly exposed populations, although this issue is still controversial. ${ }^{32}$ In addition, given the generally asymptomatic nature of chlamydial infection in both women and men, interventions based on syndromic diagnosis are likely to be of limited effectiveness in reducing chlamydia prevalence, even in female sex workers. Equal prevalences in high risk groups and the general population also suggest that more transmission may be occurring within the general population than is the case for gonorrhoea.

Fewer data are available on viral than on bacterial STIs (apart from HIV) in Cotonou. The general population prevalence of HSV-2 antibodies was moderate, at $12 \%$ in men and $30 \%$ in women in 1998, though very much higher in female sex workers at $92 \%$, and was independently associated with HIV infection in cross sectional multivariate analysis. ${ }^{33}$ Major differentials in HSV-2 prevalence exist between HIV positive and HIV negative women in the general population (69\% v 28\%), while prevalence is only slightly higher in HIV positive than in HIV negative female sex workers (95\% v 87\%). In addition, HSV-2 prevalence was significantly lower in the general population in Cotonou than in the other three cities in the four cities study (Yaoundé, Kisumu, Ndola), and there was a greater differential between prevalences in female sex workers and the general population. ${ }^{63}$ However, as for HIV, while HSV-2 prevalence is lower in low risk women in Cotonou than in the other cities, that in female sex workers is similar. We thus suggest that HSV-2 may be in a hyperendemic phase in Cotonou, with large differentials in prevalence in HIV negative high and low risk women indicating that HSV-2 transmission (at least in HIV negative people) may currently be largely fuelled through core/bridge groups.

Genital ulcers were detected in $2 \%$ of clients of female sex workers and $17 \%$ of female sex workers themselves on clinical examination. Although their aetiology in these particular studies was unknown, unpublished data (mainly from female 
sex workers) suggest that syphilis is basically absent from genital ulcers in Cotonou and that the main causative agents are herpes (HSV-2) and $H$ ducreyi (Pépin J, et al, unpublished data).

In summary, both gonorrhoea and HSV-2 prevalences are significantly higher in core/bridging groups than in the general population in Cotonou, and could be important in the enhancement of HIV transmission within and without these groups. In contrast, risk of exposure to $C$ trachomatis and syphilis appears not to be that much greater in core/bridging groups than in the general population. Finally, studies on health seeking behaviour suggest that STI treatment is often tardy and inappropriate, and may contribute to high levels of antibiotic resistance in the presence of long standing infections, even in men. Indeed, self treatment is widespread in Cotonou for any health problem, ${ }^{34}$ including STIs. ${ }^{14} 35$ Furthermore, a study on sexual partners of female sex workers has shown that antibiotics are widely used for STI prophylaxis by these men. ${ }^{36}$

\section{Conclusions}

Analysis of available data suggests that the HIV epidemic in Benin is still very much dependent on transmission from core groups, through bridging groups, to the general population of women and to female sex workers themselves; and that the number of new infections generated by the core/bridging group is very much greater than that generated within the general population, which may at this stage still account for a very small proportion of new infections. Transmission dynamics modelling of the epidemic in Cotonou, discussed in detail in another paper in the present issue, ${ }^{3}$ supports the conclusions drawn from available data that male circumcision and the sexual mixing structure in Cotonou would have contributed to containing the overall epidemic, as well as to an equal male:female ratio of HIV infections in the general population.

Interventions targeted at core and bridging groups, involving both promotion of correct condom use as well as prompt and effective health seeking behaviour for STIs, thus clearly continue to be a high priority. Evidence suggests that SIDA2 interventions targeted at both female sex workers and their clients are effective in reaching these populations, and may contribute to behavioural change and levelling/decreases in prevalence of HIV and STIs. ${ }^{137}$ These findings are supported by modelling studies, ${ }^{3}$ which suggest that the SIDA2 project may have played a role in preventing a substantial amount of new HIV and STI cases both in core groups and in the general population. In addition, the results from this latter study suggest-as would be expected because condoms decrease the risk of HIV and STI transmission to a much greater extent than STI treatment alone-that the effect of increased rates of condom use between female sex workers and their clients is considerably greater than that of treating STIs alone. Early introduction during the epidemic of the SIDA2 intervention would have helped its success. However, the modelling data also indicate that even though the SIDA2 intervention may have had an effect on HIV prevalence in Cotonou, in order to have a really significant long term impact on HIV rates, the coverage and intensity of interventions directed at high risk populations should be maximised. ${ }^{3}$

In terms of specific STIs, the data suggest that interventions targeting gonorrhoea and HSV-2-where prevalence differentials are high between core groups and the general population-should be the primary focus for core/bridge group interventions in Cotonou. Interventions targeting HSV-2 infection could have a simultaneous impact on HIV and HSV-2 infection rates in the general population, and, given the major differentials in HSV-2 prevalence that still exist in Cotonou between high and low risk women $\left(91 \%\right.$ v 30\%), ${ }^{63}$ there may still be a window of opportunity to have a significant effect on HSV-2 prevalence in the general population. In contrast, in other countries in sub-Saharan Africa, where the differential in HSV-2 prevalence between high and low risk groups is lower, ${ }^{63}$ suggesting that the STI may be in a later more endemic phase, it may be more difficult to control HSV-2 infection in the general population through targeted core group interventions.

In contrast, syphilis, which appears to be in a low endemic phase in Cotonou, should be targeted in both high risk groups and also in the general population, through routine surveillance and improvements in primary health care facilities. This is also the case for chlamydia, where, owing to its frequently asymptomatic nature, there is also an urgent need for a simple and cheap laboratory detection test that could be used in developing countries.

Our paper shows the importance of data on bridging groups (clients of female sex workers) for understanding the epidemic, as they are the link (bridging population) between high and low risk groups. The quality of information on sexual behaviour of men with female sex workers is clearly better in the prostitution context than when men are approached in the general population. This is exemplified by the differences in proportions of men in the general population who visit female sex workers, when data from men in the general population as opposed to data directly obtained from clients of female sex workers are used, and argues for studies and interventions to be directly targeted to men visiting female sex workers at prostitution venues, where the different social desirability context allows a more direct approach to sexual behaviour among clients of the sex workers.

While the paramount importance of interventions directed at core and bridging groups is clear in a situation such as that in Cotonou, some will argue that once general population prevalence reaches a certain level, interventions targeted at high risk populations are less of a priority. ${ }^{38}{ }^{39}$ We contend that even in these higher prevalence countries where more transmission occurs within the general population than in Cotonou, it is still clearly of the utmost importance to target high risk groups, because they continue to be the source for seeding new infections in bridging groups.

\section{ACKNOWLEDGEMENTS}

MA is the recipient of a research scholarship from Fonds de recherche en santé du Québec (No 970097). CABG was recipient of a MSc training award from WHO. LM-T was a recipient of a PhD training award from IDRC (International Development Research Centre).

\section{Authors' affiliations}

C M Lowndes, M Alary, Groupe de recherche en épidémiologie de I'Université Laval, Hôpital du Saint-Sacrement du CHA, Québec, Canada C M Lowndes, Department Social Science and Medicine, Imperial College, London, UK

H Meda, C A B Gnintoungbé, Project SIDA 2-Bénin, Cotonou, Bénin L Mukenge-Tshibaka, Dispensaire MST, Centre de Santé de

Circonscription Urbaine Cotonou 1, Bénin

C Adjovi, S Anagonou, Programme national de lutte contre le Sida et les MST (PNLS) du Bénin

A Buve, STD/HIV Intervention Unit, Institute of Tropical Medicine, Antwerp, Belgium

L Morison, Infectious Disease Epidemiology Unit, London School of Hygiene and Tropical Medicine, Keppel Street, London WC1, UK M Laourou, Institut National de Statistiques et d'Analyses Economiques, Bénin

L Kanhonou, Centre de recherche en reproduction humaine et en demographie (CERRHUD), Benin

\section{REFERENCES}

1 Buvé A, Caraël M, Hayes R, et al. Variations in HIV prevalence between urban areas in sub-Saharan Africa: do we understand them? AIDS 1995;9(suppl A):S103-9.

2 Wasserheit JN, Aral SO. The dynamic topology of sexually transmitted disease epidemics: implications for prevention strategies. J Infect Dis 1996; 174(suppl 2):S201-13. 
3 Boily M-C, Lowndes CM, Alary M. The impact of HIV epidemic phases on the effectiveness of core group interventions: insights from mathematical models. Sex Transm Inf 2002;78(suppl):i78-90.

4 Buvé A, Caraël M, Hayes R, et al. Multicentre study on factors determining differences in rate of spread of HIV in sub-Saharan Africa: methods and prevalence of HIV infection. AIDS

2001;15(suppl 4):S5-14

5 The Study Group on Heterogeneity of HIV Epidemics in African Cities. The multicentre study on factors determining the differentia spread of HIV in four African towns: Summary and conclusions. AIDS 2001;15(suppl 4):S127-31.

6 Morison L, Weiss H, Buvé A, et al, for the Study Group on Heterogeneity of HIV Epidemics in African Cities. Commercial sex work and the spread of HIV epidemics in four cities in sub-Saharan Africa. AIDS 2001;15(suppl 4);S61-9.

7 Mboup X, Tossou Y. Benin further analysis: knowledge, attitudes, and behaviour regarding AIDS in Benin. Calverton, Maryland, USA: Demographic and Health Surveys (DHS), Macro International Inc., 1997.

8 Alary M, Baganizi E, Guedeme A, et al. Evaluation of clinical algorithms for the diagnosis of gonococcal and chlamydial infections among men with urethral discharge or dysuria and women with vaginal discharge in Benin. Sex Transm Inf 1998;74(suppl 1):S44-9.

9 Alary $M$, Guèdèmè A, Davo N, et al. Prévalence du VIH et des MTS chez les consultants MST, les femmes enceintes et les prostituées au Bénin. SIDA 1 project, Bénin component, unpublished report, 1994.

10 Germain $M$, Alary M, Guèdèmè $A$, et al. Evaluation of a screening algorithm for the diagnosis of genital infections with Neisseria gonorrhoeae and Chlamydia trachomatis among female sex workers in Bénin. Sex Transm Dis 1997;24:109-15.

11 Meda H, Alary M, Gnintoungbé C, et al. Socio-demographic profile and trends in condom use among female prostitutes (FP) attending a STD clinic in Cotonou, Benin, West Africa. 13th World AIDS Conference, 9-1 4 July 2000; Durban, South Africa.

12 Alary M, Mukenge L, Ouedraogo LH, et al. STDs among female sex workers in Bénin: time trends and validity of a scoring algorithm. International Congress of Sexually Transmitted Diseases, Seville, Spain, 19-22 October 1997. Abstract No O165

13 Alary M, Mukenge-Tshibaka L, Anagonou S, et al. Impact of condom promotion and STD control on HIV and STD prevalence in female prostitutes in Cotonou, Benin: observations from the field in the context of a changing prostitution milieu. 13th World AIDS Conference, 9-14 July 2000; Durban, South Africa.

14 Gnintoungbé CAB. Maladies sexuellement transmissibles et infection à $\mathrm{VIH}$ chez les partenaires sexuels des prostituées à Cotonou, Bénin. Québec: Université Laval, 1999. [Mémoire de maîtrise; thesis.]

15 Lowndes CM, Alary M, Gnintoungbé CAB, et al. Management of sexually transmitted diseases and HIV prevention in men at high risk: targeting clients and non-paying sexual partners of female sex workers in Benin. AIDS 2000;14:2523-34.

16 Ministère de la Santé Publique (MSP), Service des statistiques, de la documentation et de la Recherche Opérationnelle (SSDRO). Statistiques sanitaires Année 1998. Place of publication: publisher, 1999.

17 Ministère du Plan, de la Restructuration Économique et de la Promotion de l=Emploi (MPREPE)/Institut National de la Statistique et de l'Analyse Économique (INSAE)/Macro International (1999). Résultats de l'Enquête Démographique et de Santé au Bénin (EDSB-1, 1996). Analyse départamentale: Atlantique. Rapport des statistiques sanitaires. République du Bénin: Ministère de la Santé Publique (MSP), Service des statistiques, de la documentation et de la Recherche Opérationnelle (SSDRO), 1994.

18 Ferry B, Caraël M, Buvé A, et al. Comparison of key parameters of sexual behaviour in four African urban populations with different levels of HIV infection. AIDS 2001;15(suppl 4):S41-50.

19 Lagarde E, Auvert B, Chege J, et al. Condom use and its association with HIV/STDs in four urban communities of sub-Saharan Africa. AIDS 2001;15(suppl 4):S71-8.
20 Auvert B, Buvé A, Lagarde $\mathrm{E}$, et al. Male circumcision and HIV infection in four towns in sub-Saharan Africa. AIDS 2001;15(suppl 4):s31-40.

21 Adjovi C. Surveillance epidemiologique de l'infection par le $\mathrm{VIH} / \mathrm{SIDA} / \mathrm{MST}$ en Republique du Bénin. Rapport année 1999. Benin: Ministère de la Santé, Direction Nationale de la Protection Sanitaire, Programme National de Lutte contre le SIDA et les MST (PNLS), 1999.

22 Adjovi C. Rapport de l'enquête nationale de surveillance de l'infection par le VIH au Bénin, Année 1998. Benin: Ministère de la Santé Publique (MSP), Direction Nationale de la Protection Sanitaire, Programme National de Lutte contre le SIDA et les MST (PNLS), 1998.

23 Pépin J, Sobela F, Deslandes S, et al. Aetiology of urethral discharge in Africa: the role of Mycoplasma genitalium and Trichomonas vaginalis. Bull WHO $2001 ; 79: 118-26$.

24 Mukenge-Tshibaka L, Alary M, Bernier F, et al. Detection of Neissseria gonorrhoeae in genitourinary specimens from female sex workers in Cotonou, Benin: poor diagnostic performance of the Roche Amplicor PCR with urine specimens. J Clin Microbiol 2000;38:4076-9.

25 Gnintoungbé CAB, Gomez C, Lowndes CM, et al. Profils de la prostitution au Bénin. SIDA2 project, Benin component. Unpublished report, 1999.

26 Bigot A, Zohoun I, De Bruyere $M$, et al. First cases of anti-HIV seropositivity in Benin. Presse Med 1987; 16:1102.

27 Bigot A, Bodeus M, Burtonboy G, et al. Prevalence of HIV infection among prostitutes in Benin [letter]. J Acq Immune Defic Syndr 1992:5:317-19.

28 Baganizi E, Alary M, Adjovi C, et al. Evolution de l'infection au VIH parmi les professionelles du sexe au Bénin. Xth International Conference on AIDS and STD in Africa. Abidjan, Côte d'Ivoire: 7-11 December 1997: abstract No B199.

29 UNAIDS. Report on the global HIV/AIDS epidemic. Geneva: UNAIDS/00.13E, 2000

30 Quinn TC, Wawer M, Sewankambo N, et al, for the Rakai Project Study Group. Viral load and heterosexual transmission of human immunodeficiency virus type 1. N Engl J Med 2000;342:921-9.

31 Weiss HA, Quigley MA, Hayes RJ. Male circumcision and risk of HIV infection in sub-Saharan Africa: a systematic review and meta-analysis. AIDS 2000;14:2361-70

32 Schachter J. Biology of Chlamydia trachomatis. In: Holmes KK, Sparling PF, Mardh PA, et al, eds. Sexually transmitted diseases. New York, McGraw-Hill, 1999:391-405.

33 Weiss HA, Buvé A, Robinson NJ, et al. The epidemiology of HSV-2 infection and its association with HIV infection in four urban African populations. AIDS 2001;15(suppl 4):S97-108.

34 Gomez do Espirito Santo EG, Floury B, Cissé M. Déterminants du recours aux soins dans la ville de Cotonou (Bénin). Bull WHO 1998;76:195-201.

35 Jossou PS. Itinéraires thérapeutiques des patients atteints de maladies sexuellement transmissibles à Cotonou: à propos d'un échantillon de 214 cas rencontrés dans les formations sanitaires de Cotonou. Thèse pour l'obtention de grade de Docteur en Medecine. Cotonou: Université National du Benin, Faculté des Sciences de la Santé, 1999. [Thesis.]

36 Lowndes CM, Gnintoungbé C, Alary M, et al. Clients of prostitutes in Benin: health-seeking behaviour for STDs. Denver, Colorado: 13th Meeting of International Society for Sexually Transmitted Diseases Research (ISSTDR), 11-14 July 1999.

37 Lowndes CM, Alary M, Belleau M, et al. Interventions directed at male clients of female sex workers in Cotonou, Benin, West Africa. Berlin: International Congress of Sexually Transmitted Infections, 24-27 June 2001.

38 Kamenga $\mathbf{M}$, Denison J, White $\mathrm{R}$, et al. Targeting interventions for the prevention of HIV infection in developing countries: when to begin targeting non-core groups. Washington DC: 3rd USAID HIV/AIDS Prevention Conference, 7-9 August 1995

39 Robinson NJ, Mulder D, Auvert B, et al. Type of partnership and heterosexual spread of HIV infection in rural Uganda: results from simulation modelling. Int J STD AIDS 1999;10:718-25. 